Journal of Economics and Behavioral Studies

Vol. 4, No. 9, pp. 523-531, Sep 2012 (ISSN: 2220-6140)

\title{
Asymmetric Price Transmission between Local and Imported Rice Prices in Burkina Faso
}

\author{
Emmanuel Asane Otoo \\ University of Bonn, Germany \\ asane.otoo@yahoo.com
}

\begin{abstract}
The study of how price signals in imported rice market influences prices in the local rice market is essential in understanding the inter-relationship between these prices and how soaring global food prices affect prices of locally produced agricultural commodities. This study uses a set of cointegration and error correction models with symmetric and asymmetric adjustment towards the long-run equilibrium to investigate the long-run relationship between local and imported rice prices and the extent to which imported rice prices are transmitted to local rice prices in Burkina Faso. Using national average consumer prices from January 2000 to June 2011, empirical results from the Engle-Granger and Johansen cointegration tests show that consumer price of local rice is significantly integrated with the imported rice market prices. Both threshold cointegration and asymmetric error correction models indicate that consumer prices of local rice respond asymmetrically to shocks from the imported rice price. Specifically, local rice prices respond rapidly to negative shocks while positive shocks take substantial amount of time to be transmitted. These findings provide clear empirical evidence with respect to the impact of imported rice prices on local rice prices and the role of profit-seeking traders in maintaining or increasing the price wedge between the two prices in Burkina Faso.
\end{abstract}

Keywords: Cointegration, adjustment, integration, threshold, shocks

\section{Introduction}

Recent booms and subsequent decreases in agricultural commodity prices on the world market have opened up relevant questions about the impact of these fluctuations on domestic prices in developing countries. There is widespread concern that hunger, poverty and food insecurity will increase sharply across the world especially in poor countries that are heavily dependent on staple food imports. This is because extreme fluctuations in prices of agricultural commodities do not only threaten the food security of millions of people but also the economic recovery and social stability of developing countries (Ortiz et al., 2011). The impact is compounded as more urban households and other net buyers of food lose purchasing power due to rising food costs and are plunged into poverty. Although Burkina Faso is food sufficient in other cereals such as maize, millet and sorghum (DTIS, 2007), the country imports about $60 \%$ of its national rice consumption demand from the world market (USDA, 2012). As such, the world market prices have significant impact on consumer prices of imported rice, which invariably influences local rice prices since producers, and traders adjust their local rice prices in accordance with the changes in imported rice prices. It is therefore, important to have a good understanding of the functioning of these markets and to examine how they are integrated. Thus, the objective of this study was to examine the long-run relationship between consumer prices of local and imported rice and to determine whether the response of local rice prices to imported rice prices is symmetric or asymmetric. As policy makers strive to implement policies to increase local production of rice to reduce imports, prices and ensure food security, the findings from this study will offer a clear understanding of how price development in the imported rice market influences prices of locally produced rice.

\section{Literature Review}

The concept of cointegration hinges on the fact that, non-stationary variables may nonetheless possess longrun equilibrium relationships and thus, have the tendency to move together in the long-run (Engle \& Granger, 1987). However, the cointegration and its corresponding error correction models used in most studies implicitly assume that the tendency to move towards a long-run equilibrium is present every time (Balke \& 
Fomby, 1997). However, Balke \& Fomby (1997) pointed out that the presence of fixed costs of adjustment may prevent economic agents from adjusting continuously and movement towards equilibrium may not occur in every period. Thus, economic agents act to move the system back towards the equilibrium only when the deviation from the equilibrium exceeds a critical threshold (which is a function of transaction and adjustment costs, economic risk etc) where the benefits of adjustment exceed the costs. Threshold autoregressive (TAR) models capture this economic behaviour by ensuring that deviations from the equilibrium exceed a certain threshold before provoking a corresponding equilibrating price adjustment that lead to market integration (Goodwin \& Piggot, 2001). These models estimate a threshold in the price margin between two markets resulting in threshold effects that occur when larger shocks (i.e. shocks above the threshold) bring about a different response than small shocks. Thus, threshold models capture the degree to which the market violates the spatial arbitrage condition and measures the speed with which it eliminates these violations (Fackler \& Goodwin, 2001). Hence, these models are essential when investigating the asymmetric adjustments process envisioned holding for many economic phenomena. Asymmetry price transmission however, reflects different distribution of welfare. It indicates that, some economic agents are not benefiting from price reductions or increase that they would have enjoyed under symmetric conditions. The disparities with respect to the gains and losses due to price changes occur because the asymmetric condition alters the timing and/or the size of the welfare changes that are associated with price changes.

\section{Methodology}

Linear cointegration test: The Engle-Granger (EG) cointegration test, proposed by Engle \&Granger (1987) and the Johansen test for cointegration were used to test the existence of long-run relationship between the two prices. The EG test is a two-step residual-based test for cointegration and symmetric adjustment between non-stationary variables. The test estimates the long-run equilibrium relationship between non-stationary prices e.g. local rice price, $P_{t}^{l}$ and imported rice price, $P_{t}^{i}$ in the form:

$P_{t}^{l}=\alpha_{o}+\alpha_{1} P_{t}^{i}+\mu_{t}$

Where $\alpha_{0}$ is an arbitrary constant that accounts for the differential (transfer and quality differences), $\alpha_{1}$ denotes the long-run price transmission elasticity and $\mu_{t}$ is a random error term with a constant variance? Under the null hypothesis that $P_{t}^{l}$ and $P_{t}^{i}$ are not cointegrated, the error term should be non-stationary. The stationarity test on the error terms is conducted by testing the significance of the coefficient of adjustment $(\rho)$, which captures the rate of adjustment towards the long-run equilibrium in Equation (2) below:

$\Delta \mu_{t}=\rho \mu_{t-1}+\varepsilon_{t}$

Where $\varepsilon_{t}$ is a white noise residual? Within the framework of Equation (2), rejection of the null hypothesis of no cointegration (i.e. $H_{o}: \rho=0$ ) implies that, the error term (the price spread/margin) in Equation (1) is stationary and the prices are cointegrated.

Johansen test: The Johansen (1988) cointegration test which permits more than one cointegrating relationships was used to verify the EG test and is specified in Equation (3).

$\Delta x_{t}=\pi x_{t-1}+\omega_{t}$

Where $x_{t}$ is an $(\mathrm{n} \times 1)$ vector of random variables all integrated of order $1, \pi$ is an $(\mathrm{n} \times \mathrm{n})$ matrix, $\omega_{t}$ is an $(\mathrm{n} \times$ 1) vector of normally distributed disturbances. The underlying mechanism of the above formulation is the estimation of $\pi$ and determining its rank. It is important to state that, unlike the Engle and Granger approach, any conclusion drawn from the Johansen procedure is independent of the choice of dependent variables.

Test for threshold cointegration and asymmetry adjustment: The cointegration tests and extensions from the Engle \& Granger (1987) approach are misspecified if the adjustment is asymmetric (Enders \& Granger, 1998; Enders \& Siklos, 2001). As a result, Enders \& Granger (1998) as well as Enders \& Siklos (2001) introduced asymmetric adjustment by considering a one threshold and two-regime autoregressive model that is represented as: 
$\Delta \mu_{t}=\rho_{1} H_{t} \mu_{t-1}+\rho_{2}\left(1-H_{t}\right) \mu_{t-1}+\varepsilon_{t}$

where $H_{t}$ is a Heaviside indicator function which is equal to either:

$I_{t}=\left\{\begin{array}{l}1 \text { if } \mu_{\mathrm{t}-1} \geq \tau \\ 0 \text { if } \mu_{\mathrm{t}-1}<\tau\end{array}\right\}$

or

$M_{t}=\left\{\begin{array}{l}1 \text { if } \Delta \mu_{\mathrm{t}-1} \geq \tau \\ 0 \text { if } \Delta \mu_{\mathrm{t}-1}<\tau\end{array}\right\}$

where $\tau$ is the value of the threshold, $\left\{\varepsilon_{t}\right\}$ is a sequence of zero mean, constant-variance random variables such that $\varepsilon_{t}$ is independent of $\mu_{j}$ and $\rho_{1}$ and $\rho_{2}$ are the long-run adjustment coefficients. The necessary and sufficient conditions for convergence and stationarity of $\left\{\mu_{t}\right\}$ is $\rho_{1}<0, \rho_{2}<0$ and $\left(1+\rho_{1}\right)\left(1+\rho_{2}\right)<1$ for any value of $\tau$ (Petrucelli \&Woolford, 1984; Enders \& Siklos, 2001). Models estimated using Equations (1), (4) and (5) are termed Threshold Autoregressive models (TAR) while that of Equations (1), (4) and (6) are called Momentum-Threshold Autoregressive models (M-TAR).

In testing for threshold cointegration within both the TAR and M-TAR specifications, the $t$-statistics for the null hypothesis $\rho_{1}=0, \rho_{2}=0$ and the $F$-statistics for the joint hypothesis: $\rho_{1}=\rho_{2}=0$ were compared to the appropriate critical values computed by Enders \& Siklos (2001). However, if the $\mu_{t}$ sequence is stationary, the least square estimates of $\rho_{1}$ and $\rho_{2}$ have an asymptotic multivariate normal distribution (Enders \& Siklos, 2001). Therefore, if the null hypothesis $H_{0}: \rho_{1}=\rho_{1}$ is rejected using the $F$-statistic, then the TAR and M-TAR models are capable of capturing signs of asymmetry. The threshold values $(\tau)$ were set to zero and subsequently estimated following the methodology proposed by Chan (1993). Chan's methodology involves a grid search over the potential threshold values in both the TAR and M-TAR models to select the value that has the lowest residual sum of square. The value yielding the lowest residual sum of square was

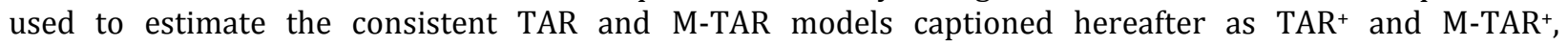
respectively.

Asymmetric Error Correction model: Confirmation of cointegration and asymmetric adjustments from the threshold models justify the estimation of an asymmetric error correction model, which estimates the speed at which local rice price return to equilibrium after a change in the imported rice price. The specification is as follows:

$$
\Delta P_{1 t}^{l}=\alpha_{0}+\rho_{1 . i} H_{t} \mu_{t-1}+\rho_{2 . i}\left(1-H_{t}\right) \mu_{t-1}+\sum_{j=0}^{k} \gamma_{1 j} \Delta P_{2 t-j}^{r}+\sum_{j=1}^{k} \lambda_{1 j} \Delta P_{1 t-j}^{l}+\varepsilon_{i t}
$$

Where $\rho_{1 i}$ and $\rho_{2 i}$ are the adjustment coefficients (i.e. the rate at which the model re-equilibrates), $\gamma_{1}$ denotes short-run price transmission elasticity and $H_{t} \mu_{t-1}$ and $\left(1-H_{t}\right) \mu_{t-1}$ are hereafter denoted as $Z_{-}$plust $t_{t-1}$ and $Z_{-}$minus $t_{t-1}$, respectively.

Data sources: The data used in this study was obtained from the Ministry of Agriculture, Burkina Faso. The data consist of concurrent average national monthly consumer prices of local and imported rice in CFA Franc per Kilogram (CFA franc/kg) from January 2000 to June 2011 (i.e. 136 observations). The analysis was conducted using the logarithmic values of the nominal prices.

\section{Results and Discussion}

Unit root test: Conventional unit root tests such as the Augmented Dickey-Fuller (ADF) and Phillips-Perron (PP) tests were used to render a verdict as to whether the price series under investigation exhibits unit root 
or stationary behavior. The tests were conducted for all series in levels and in first difference with and without trend and the results are presented in Table 4 in the appendix. Using the optimal number of lags determined by Akaike information criterion (AIC) and Bayesian information criterion (BIC), the ADF and PP tests found the existence of unit root in levels at all conventional significance levels in both prices. More so, at all significance levels, both tests rejected the existence of unit root in the first difference of all the series indicating that all the prices exhibit unit root processes and are integrated of order one.

Linear cointegration test: Estimation results of Engle-Granger methodology as a test for long-run integration between real consumer prices of local and imported rice is presented in Equation (8) with $t$ statistic in parenthesis.

$$
\begin{aligned}
L P_{r t}= & -0.791+0.832 I P_{r t}+\hat{\mu}_{\mathrm{t}} \\
& (-4.91)(29.52) \\
L P_{r t}= & 1.409+0.716 I P_{r t}+0.001 t_{t}+\hat{\mu}_{\mathrm{t}} \\
& (6.55) \quad(18.31)
\end{aligned}
$$

Where $\mathrm{LP}_{\mathrm{rt}}$, and $\mathrm{IP}_{\mathrm{rt}}$, are logarithmic values of nominal consumer prices of local and imported rice, respectively. Similarly, Equation (8) was further estimated as presented in Equation (9) by including a trend variable to check how the results differ with the inclusion of trend. The respective residuals from both estimations (with and without trend) were used separately in estimating Equation (2) above and the results are presented in Table 1. The Ljung-Box Q-statistic in all the specifications shows that, the residuals $\left(\varepsilon_{t}\right)$ from the models exhibit a white noise process confirming the absence of residual autocorrelation.

Table 1: Augmented Engle-Granger test for cointegration

\begin{tabular}{lllllll}
\hline & & t-statistics & $\mathbf{1 \%} \mathbf{C V}$ & $\mathbf{5 \%} \mathbf{C V}$ & $\mathbf{1 0 \%} \mathbf{C V}$ & $\mathbf{Q ( 4 )}[\boldsymbol{p}$-value] \\
\hline \multirow{2}{*}{ Model } & (without trend) & -4.68 & -3.48 & -2.88 & -2.58 & $2.74[0.60]$ \\
& (with trend) & -4.64 & -4.03 & -3.44 & -3.15 & $2.95[0.57]$ \\
\hline
\end{tabular}

CV: critical values from Mackinnon (1990, 2010); Q (4): Ljung-Box statistic that the first 4 of the residual autocorrelations are jointly equal to zero.

Both the model with trend and that without trend soundly reject the null hypothesis of unit root $(\rho=0)$ in the $\hat{\mu}_{t}$ series at all significance levels. The rejection of the null hypothesis clearly shows that the residuals in Equations (8) and (9) are stationary. This implies that the consumer prices of local and imported rice have a significant long-run relationship.

Table 2: Johansen cointegration test

\begin{tabular}{lllll}
\hline Null Hypothesis & $\begin{array}{l}\text { Alternative } \\
\text { hypothesis }\end{array}$ & & $\begin{array}{l}\mathbf{5 \%} \\
\text { Value }\end{array}$ & $\begin{array}{l}\text { Critical } \\
\text { Value }\end{array}$ \\
\hline$\lambda_{\text {trace tests (with constant) }}$ & & $\lambda_{\text {trace value }}$ & & \\
$r=0$ & $r>0$ & $24.314^{* * *}$ & 15.41 & 20.04 \\
$r \leq 1$ & $r>1$ & 0.270 & 3.76 & 6.65 \\
$\lambda_{\max }$ tests (with constant) & & $\lambda_{\max }$ value & & \\
$r=0$ & $r=1$ & $24.044^{* * *}$ & $14 . .07$ & 18.63 \\
$r=1$ & $r=2$ & 0.270 & 3.76 & 6.65 \\
\hline$* * *$
\end{tabular}

${ }^{* * *}$ implies the rejection of null at $1 \%$ significance level; $r$ denotes cointegrating rank

Both $\lambda_{\text {trace }}$ and $\lambda_{\max }$ statistics from the Johansen (1988) methodology, which also test for linear cointegration soundly, reject the null hypothesis of no cointegration in favor of the alternative hypothesis of one cointegrating rank. The trace statistic rejected the null hypothesis of no cointegrating vector at $1 \%$ significance level but could not reject the null of one or less than 1 cointegrating vector. In the case of $\lambda_{\max }$ statistic, the null hypothesis of no cointegration $(\mathrm{r}=0)$ is rejected at $1 \%$ level of significance in favor of the 
specific alternative hypothesis of one cointegrating vector $(r=1)$. Hence both the $\lambda_{\text {trace }}$ and $\lambda_{\max }$ statistics clearly confirms the result from the EG test that the consumer prices of local rice and imported rice are significantly integrated in the long run. This finding is not surprising because, generally, local rice is a substitute for imported rice. Therefore, as the price of imported rice increases: shifting demand to local rice, the local rice prices also adjust since producers and retailers take advantage of the increasing demand. In effect, price developments in the imported rice market greatly influence price changes in the local rice market in both short and long run.

Threshold cointegration and asymmetric adjustment: Table 3 presents the results of the asymmetric cointegration models. The point estimate of $\rho_{1}$ and $\rho_{2}$ in both the TAR and M-TAR models (threshold $=0$ ) suggest convergence with different rate of adjustments. The estimated $\Phi$ and $\Phi(M)$-statistics for the null hypothesis of no cointegration $\left(\rho_{1}=\rho_{2}=0\right)$ for the TAR and M-TAR models are respectively significant at all significance levels since they exceed the $1 \%$ critical values (8.82 and 8.46) reported in Enders \& Siklos (2001). Hence, the null hypothesis of no cointegration is rejected in favor of cointegration. The $p$-value for the null hypothesis of symmetric adjustment: $\rho_{1}=\rho_{2}$ is also rejected at $1 \%$ significance level within the TAR and M-TAR specifications.

Table 3: Asymmetric cointegration test

\begin{tabular}{|c|c|c|c|c|}
\hline & \multicolumn{2}{|c|}{ Normal Thresholds } & \multicolumn{2}{|c|}{ Consistent thresholds } \\
\hline & TAR & M-TAR & TAR $^{+}$ & M-TAR ${ }^{+}$ \\
\hline Threshold value & 0 & 0 & -0.049 & -0.018 \\
\hline$\rho_{1}$ & $\begin{array}{l}-0.24 \\
(-2.26)\end{array}$ & $\begin{array}{l}-0.25 \\
(-2.34)\end{array}$ & $\begin{array}{l}-0.23 \\
(-2.22)\end{array}$ & $\begin{array}{l}-0.28 \\
(-2.92)\end{array}$ \\
\hline \multirow[t]{2}{*}{$\rho_{2}$} & -0.61 & -0.60 & -0.70 & -0.83 \\
\hline & $(-4.99)$ & $(-4.94)$ & $(-5.28)$ & $(-5.67)$ \\
\hline lags & 6 & 6 & 6 & 6 \\
\hline$Q(4)$ & 0.99 & 0.98 & 0.99 & 0.98 \\
\hline$Q(8)$ & 0.96 & 0.99 & 0.89 & 0.99 \\
\hline$\rho_{1}=\rho_{2}=0\left(\Phi\right.$ or $\left.\Phi^{*}\right)$ & $12.76^{* * *}$ & $12.54^{* * *}$ & $14.42^{* * *}$ & $16.78^{* * *}$ \\
\hline$\rho_{1}=\rho_{2}(\mathrm{~F}-\mathrm{Test})$ & $0.008^{* * *}$ & $0.009^{* * *}$ & $0.002^{* * *}$ & $0.002^{* * *}$ \\
\hline AIC & -480.83 & -480.44 & -483.74 & -487.74 \\
\hline BIC & -457.83 & -457.44 & -460.74 & -464.74 \\
\hline
\end{tabular}

$t$-statistics are in parenthesis; $\mathrm{Q}(\mathrm{k}): p$-value of the Ljung-Box statistic that the

first $(\mathrm{k})$ of the residual autocorrelations are jointly equal to zero; ${ }^{* *}$ implies

$1 \%$ significance level; $\mathrm{TAR}^{+}$and $\mathrm{M}-\mathrm{TAR}^{+}$are the consistent threshold models.

Following the approach of Chan (1993), the respective consistent estimates of the threshold within the $\mathrm{TAR}^{+}$

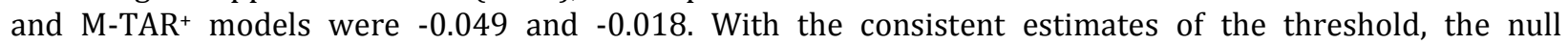
hypothesis of no cointegration is rejected at all significance levels within both the $\mathrm{TAR}^{+}$and M-TAR ${ }^{+}$models. Similarly, the symmetric adjustment hypothesis is also rejected at $1 \%$ significance level. Comparing the four models in terms of the model that best captures the asymmetric mechanism, both the AIC and BIC ruled in

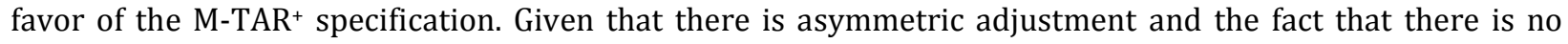
presumption as to whether $\rho_{1}$ should be greater or smaller than $\rho_{2}$, it is intriguing to note that the speed of adjustment is faster when the discrepancy is below its long-run equlibrium value $\left(\Delta \mu_{t-1}<-0.018\right)$. The long-run adjustment coefficients shows that $83 \%$ of any negative deviation from the equilibrium caused by an increase in the consumer price of imported rice or a decrease in the consumer price of local rice is eliminated within a month. Conversely, $28 \%$ of any positive deviation is eliminated within a month. Obviously, positive discrepancies exhibit high level of persistence with respect to the rate of adjustment. 
Error correction model: Confirmation of cointegration with M-TAR adjustment paves way to estimate an asymmetric error correction model to examine the short and long-run dynamics of the prices as presented in Table 4. The AIC and BIC were used to determine the appropriate lag length to ensure a more parsimonious model. Test for the null hypothesis of no serial correlation and conditional heteroscedasticity were conducted using the Ljung-Box and the ARCH (1) test to ensure statistical adequacy and appropriate inferences. The $F$ statistic $[\mathrm{F}(5,130)=8.78, p$-value $=0.00]$ which measures the significance of all coefficients including the error correction terms was found to be significant. As a result, the null hypothesis of market segmentation i.e. changes in consumer price of local rice do not respond to changes in consumer price of imported rice is rejected. Estimates of the long-run coefficient of adjustments show that, the consumer price of local rice respond significantly to both positive and negative discrepancies from the long-run equilibrium price relationship with consumer price of imported rice.

Table 4: Asymmetric error correction model

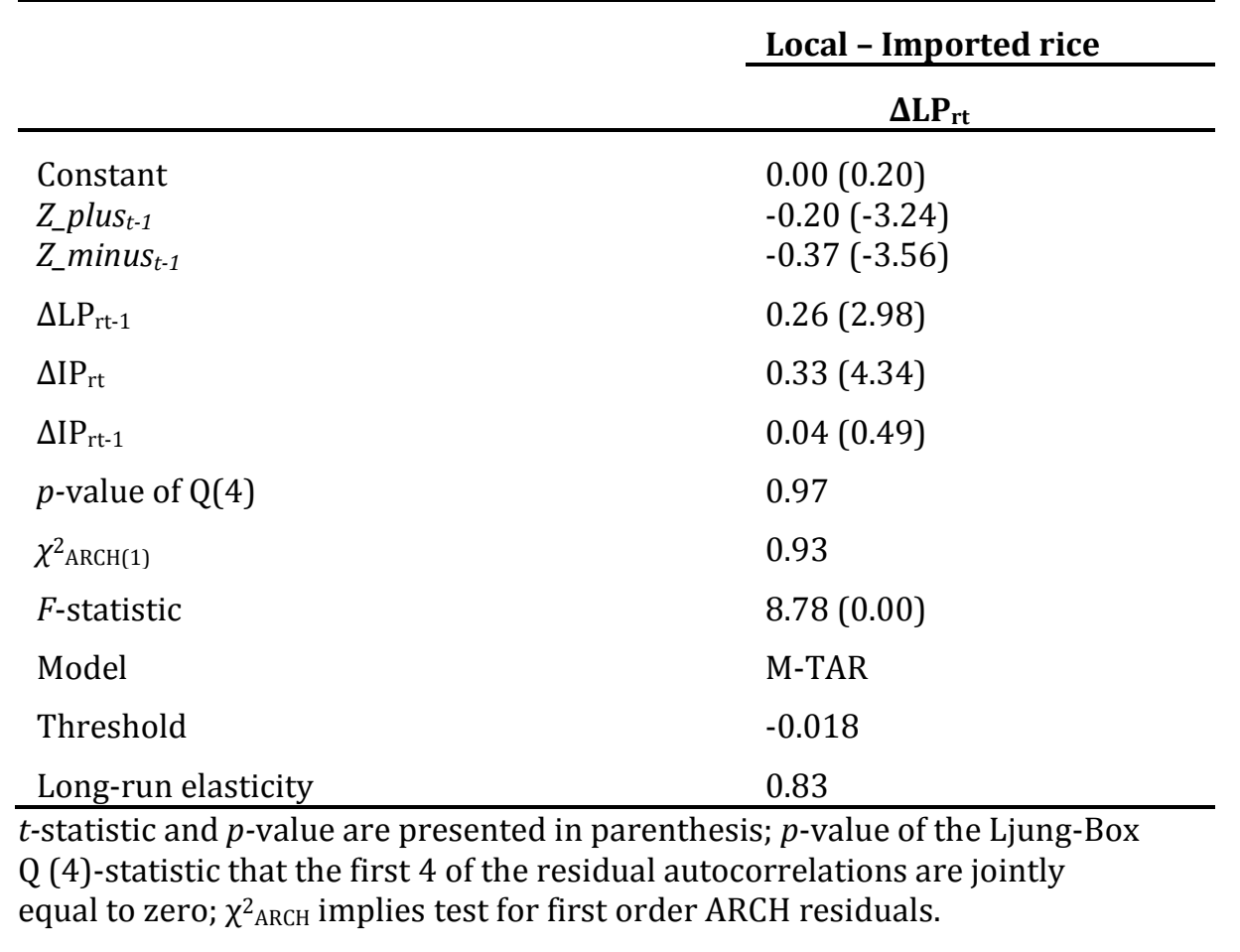

The $t$-statistics for the error correction terms (i.e. $z_{-} p l u s_{t-1}$ and $z_{-}$minus $s_{t-1}$ ) are all significant at conventional significance levels. The different estimates of the long-run adjustment coefficients $(-0.20$ and -0.37$)$ imply that, the consumer price of local rice adjusts to eliminate $20 \%$ of a unit positive change from the equilibrium. In contrast, $37 \%$ of any negative deviation from the equilibrium relationship is eliminated within a month. Apparently, there are substantial differences in terms of the rate of adjustment with positive shocks ${ }^{1}$ to the consumer price of local rice showing some amount of persistence. From Equation (8), the long-run price transmission elasticity was estimated to be 0.83 indicating that in the long run, $83 \%$ of any unit change in the consumer price of imported rice is transmitted to the consumer price of local rice. In addition, the short-run price transmission elasticity was significant and was estimated to be 0.33 . This implies that the consumer price of imported rice Granger-cause the consumer price of local rice. Thus, a unit increases in the consumer price of imported rice results in a 33\% instantaneous increase in the consumer price of local rice. The 33\% increase in local rice price results in a negative shock ${ }^{2}$ to the marketing margin by reducing the per unit equilibrium margin between the two prices by 0.67 units. The reduction in the marketing margin provokes local rice retailers to gradually increase local rice prices in the ensuing months to eliminate the deviation. Thus, the 0.67 unit reduction in the margin is eliminated asymptotically by 0.37 units per month. On the other

\footnotetext{
${ }^{1}$ Positive shock defined as any shock that stretches the marketing margin

${ }^{2}$ Negative shock: any shock that squeezes the marketing margin
} 
hand, a unit decrease in imported rice price elicits a 33\% instantaneous price decrease in the local rice price. The phenomenon increases per unit marketing margin by 0.67 units (i.e. positive shock to the margin) and the increase in the margin are eliminated by 0.20 units per month.

Figure 1: Response of local rice price to shocks in imported rice price. LPS: Local rice price response to positive shocks; LNP: Local rice price response to negative shock.

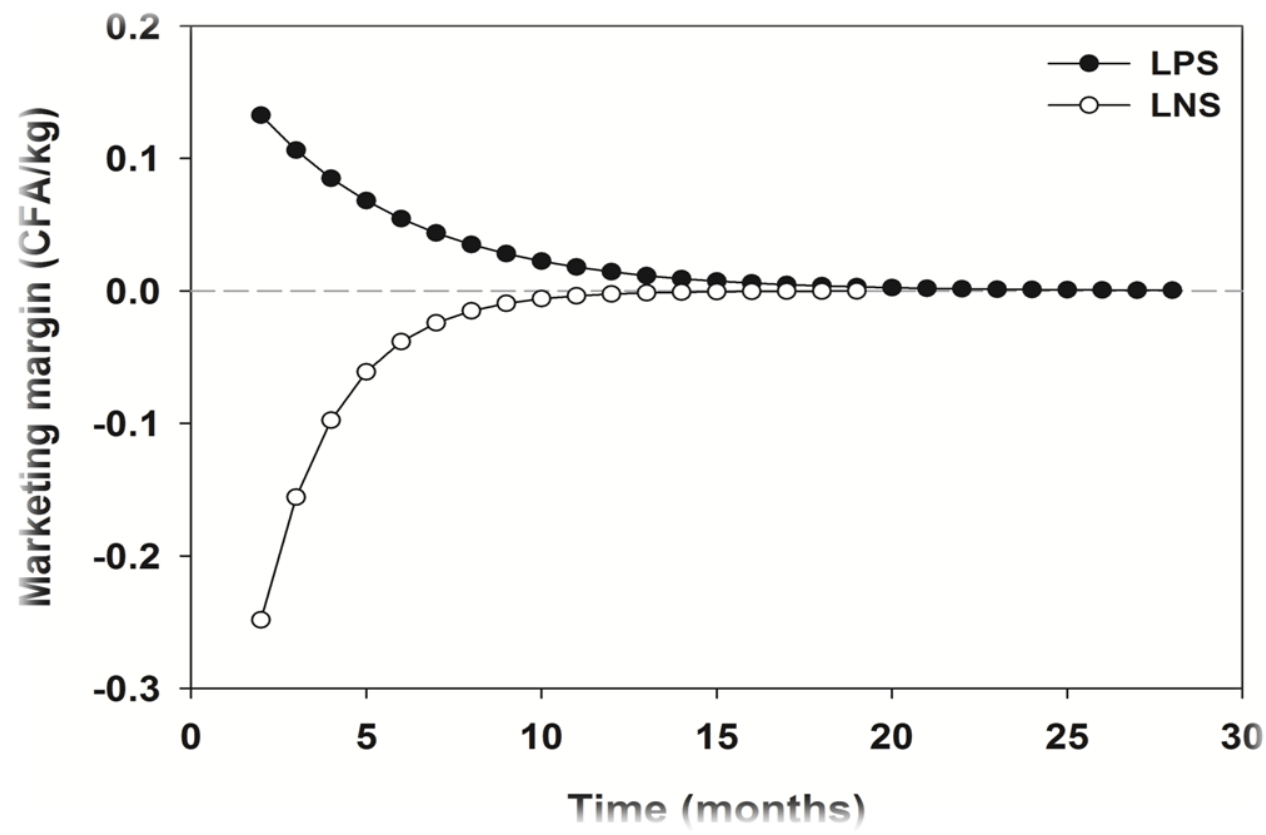

The result from the error correction model was used to formulate an impulse response function, which captures the dynamic response of the local rice prices to price changes in the imported rice market as well as the time path, or the amount of time required for the system to re-equilibrate. Figure 1 illustrates the response of local rice to positive (LPS) and negative (LNP) shocks from imported rice price. As evidenced from Figure 1, it takes approximately 11 months for a unit change in the marketing margin to re-equilibrate after the incidence of a negative shock (i.e. an increase in imported rice prices) while a unit positive shock to the marketing margin takes approximately 20 months to converge to equilibrium. Obviously, any negative shock that squeezes the margin adjust to equilibrium faster while positive shocks that stretches the margin exhibit substantial amount of persistence.

\section{Conclusion}

Using consumer prices of Burkinabe local and imported rice from January 2000 - June 2011 sample periods, the Engle-Granger; Johansen and the Enders \& Siklos tests provided strong and clear evidence in support of significant long-run market integration between the local rice and the imported rice markets. Evidence of asymmetric adjustment was found such that, increases in imported rice prices are transmitted rapidly to the consumer price of local rice while price reduction takes longer periods to get through to the local rice market. This asymmetric price transmission is due to the behavior of marketing agents/trader to maintain the equilibrium price margin between the two prices when there is a negative deviation from the equilibrium. However, traders are hesitant in passing on the price changes when there is positive shock to the margin and this behavior increases their profit margins at the expense of consumers.

Acknowledgement: The author is grateful to Emmanuel Arthur (PhD Fellow), Aarhus University for his valuable support. 


\section{References}

Balke, S. N. \& Fomby, T. B. (1997). Threshold cointegration. International Economic Review, 38, 627-645.

Chan K. S. (1993). Consistency and limiting distribution of the least squares estimator of a threshold autoregressive model. The Annals of Statistics, 21(1), 520-533.

DTIS. (2007). The Challenge of export diversification for landlocked countries, Burkina Faso. Diagnostic Trade Integrated Study (DTIS) for the Integrated Framework program.

Enders, W. \& Granger, C. W. J. (1998). Unit-root tests and asymmetric adjustment with an example using the term structure of interest rates. Journal of Business and Economic Statistics, 16, 304-311.

Enders, W. \& Siklos, P. L. (2001). Cointegration and threshold adjustment. Journal of Business and Economic Statistics, 19(2), 166-175.

Engle, R. F. \& Granger, C. W. J. (1987). Cointegration and error correction: representation, estimation and testing. Econometrica, 55, 251-280.

Fackler, P. \& Goodwin, B. K. (2001). Spatial market integration. Handbook of Agricultural Economics, Amsterdam: North Holland.

Goodwin, B. K. \& Piggott, N. (2001). Spatial Market Integration in the Presence of Threshold Effects. American Journal of Agricultural Economics, 83, 302-317.

Johansen, S. (1988). Statistical analysis of co-integrating vectors. Journal of Economic Dynamics and Control, $12,231-254$.

MacKinnon, J. G. (1990 \& 2010). Critical Values for Cointegration Tests. Queen's Economics Department, Working Paper No. 1227, Queen's University, Ontario, Canada.

Ortiz, I., Chai, J. \& Cummins, M. (2011). Escalating food prices: the threat to poor households and policies to safeguard a recovery for all. Social and economic policy working paper, UNICEF policy and practice.

Petrucelli, J. \& Woolford, S. (1984). A Threshold AR (1) Model. Journal of Applied Probability, 21, 270-286.

USDA (2012). Grain and Feed Annual. 2012 West Africa Rice Annual, United States Department of Agriculture (USDA).

\section{Appendix}

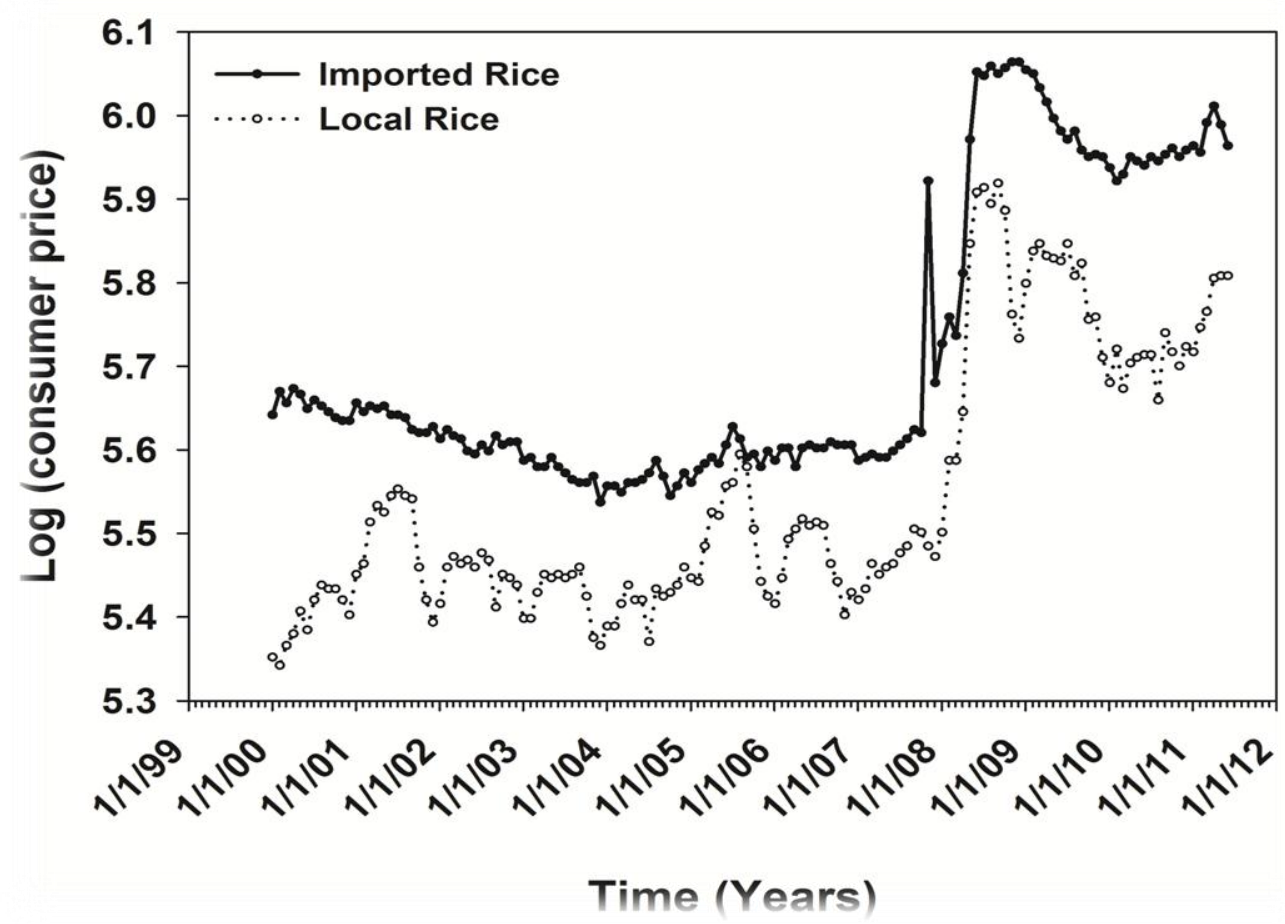

Appendix 1: Graph of log of consumer prices of local and imported rice 
Appendix 2: ADF and PP unit root test on consumer prices of local and imported rice

Levels

T-statistic (lags)

ADF

Consumer price of local rice

\begin{tabular}{lllllllll} 
Intercept & -1.49 & $(2)$ & -1.41 & Non-stationary & -7.35 & $(1)$ & -9.29 & Stationary \\
Intercept + trend & -2.63 & $(2)$ & -2.47 & Non-stationary & -7.33 & $(1)$ & -9.26 & Stationary \\
& \multicolumn{7}{c}{ Consumer price of imported rice } \\
Intercept & -0.36 & $(2)$ & -0.67 & Non-stationary & -9.19 & $(1)$ & -14.93 & Stationary \\
Intercept + trend & -1.69 & $(2)$ & -1.88 & Non-stationary & -9.22 & $(1)$ & -14.98 & Stationary \\
\hline
\end{tabular}

Newey-west lags for all PP $=4$ and optimal lags for ADF test selected using AIC and BIC

ADF and PP critical values (intercept only): $1 \%=-3.49,5 \%=-2.89$ and $10 \%=-2.56$

$\mathrm{ADF}$ and PP critical values (intercept + trend): $1 \%=-4.03,5 \%=-3.45$ and $10 \%=-3.15$ 1st difference

T-statistic (lags)

ADF

PP Decision

(1) -14.98 Stationary 